\title{
Peristaltic Transport of Couple Stress fluids In a Uniform and Non-Uniform Annulus
}

\author{
Asha.S.K \\ Department of Studies and Research in Mathematics, Karnatak University, Dharwad-500003, Karnataka, \\ India \\ as.kotnur2008@gmail.com
}

\section{ABSTRACT}

The aim of the present investigation is to study the peristaltic transport through the gap between coaxial tubes, where the outer tube is non uniform and the inner tube is rigid. The necessary theoretical results such as viscosity, pressure gradient and friction force on the inner and outer tubes have been obtained in terms of couple stress parameter. Out of these theoretical results the numerical solution of pressure gradient, outer friction, inert friction and flow rate are shown graphically for the better understanding of the problem.

Keyword: Peristaltic transport; Couple Stress Fluids

\section{INTRODUCATION}

Peristalsis is now well known to physiologists to be one of the major mechanisms for fluid transport in many biological systems. In particular, a mechanism may be involved in swallowing food through the esophagus, in urine transport form the kidney to the bladder through the urethra, in movement of chyme in the gastro -intestinal tract, in the transport of spermatozoa in the ductus efferent of the male reproductive tracts and in the cervical canal, in movement of ovum in the female fallopian tubes, in the transport of lymph in the lymphatic vessels, and in the vasomotion of small blood vessel such as arterioles, venules and capillaries. In addition, peristaltic pumping occurs in many practical applications involving biomechanical system. Also, finger and roller pumps are frequently used for pumping corrosive or very pure materials so as to prevent direct contact of the fluid with the pump's internal surfaces.

A number of analytical [1-8], numerical and experimental [9-13] studies of peristaltic flows of different fluids have been reported. A summary of most of the investigation reported up to the year 1983, has been presented by Srivastava and Srivastava [14], and some imported contribution of recent year, are reference in Srivastava and Saxsen [15]. Physiological organs are generally observed have the form of a non-uniform duct $[16,17]$. In particular, the vas deferens in rhesus monkey is in the form of a diverging tube with a ration of exit to inlet dimensions of approximately four [18]. Hence, peristaltic analysis of a Newtonian fluid in a uniform geometry cannot be applied when explaining the mechanism of transport of fluid in most bio-systems. Recently, Srivastava et al [19] and Srivastava and Srivastava [20] studied peristaltic transport of Newtonian and non-Newtonian fluids in non-uniform geometries.Asha and Rathod [23,24] studied the effect of magnetic on peristaltic motion in uniform and non-uniform annulus. Rathod and Sridhar [25] showed the effect of couple stress fluid on peristaltic transport in a uniform and non- annulus porous media.

With the above discussion in mind, we propose to study the peristaltic transport of a viscous incompressible fluid (creeping flow) through the gap between coaxial tubes, where the outer tube is non-uniform and has a sinusoidal wave travelling down its wall and the inner one is a rigid, uniform tube and moving with a constant velocity. This investigation may have application in many clinical applications such as the endoscopes problem.

\section{FORMULATION OF THE PROBLEM}

Consider the flow of an incompressible Newtonian fluid through coaxial tubes such that the outer tubes is non-uniform and has a sinusoidal wave traveling down and inner one rigid, and moving with a constant velocity. The geometry of the wall surface is

$$
\begin{aligned}
& r_{1}^{\prime}=a_{1}, \\
& r_{2}^{\prime}=a_{2}+b \operatorname{Sin}\left(\frac{2 \pi}{\lambda}\left(x^{\prime}-c t\right)\right)
\end{aligned}
$$

With

$$
a_{2}\left(z^{\prime}\right)=a_{20} k z^{\prime}
$$

With $a_{1}$ is the radius of the inner tube $a_{2}\left(z^{\prime}\right)$ is the radius of the outer tube at axial distance $z^{\prime}$ from inlet, $a_{20}$ is the radius of the outer tube at the inlet, $\mathrm{k}(<<1)$ is the constant whose magnitude depends on the length of the outer tube, $b$ is the amplitude, $\lambda$ is the wave length, $\mathrm{c}$ is the propagation velocity, and $\mathrm{t}$ is the time. We choose a cylindrical coordinate system $\left(r^{\prime}, z^{\prime}\right)$ where the $z$-axis lies along the centreline of the inner and the outer tubes and $r$ is the distance measured radially. 


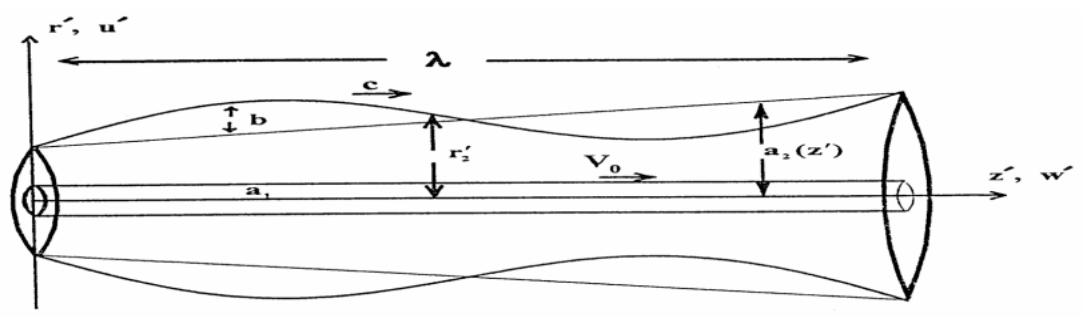

The equation of motion of the flow in the gap between the inner and the outer tubes are

$\frac{1}{r^{\prime}} \frac{\partial\left(r^{\prime}, u^{\prime}\right)}{\partial r^{\prime}}+\frac{\partial\left(w^{\prime}\right)}{\partial z^{\prime}}=0$

$\rho\left\{\frac{\partial u^{\prime}}{\partial t^{\prime}}+u^{\prime} \frac{\partial u^{\prime}}{\partial r^{\prime}}+w^{\prime} \frac{\partial u^{\prime}}{\partial z^{\prime}}\right\}=-\frac{\partial p^{\prime}}{\partial r^{\prime}}+\mu\left\{\frac{\partial}{\partial r^{\prime}}\left(\frac{1}{r} \frac{\partial\left(r^{\prime}, u^{\prime}\right)}{\partial r^{\prime}}\right)+\frac{\partial^{2} u^{\prime}}{\partial z^{\prime 2}}\right\}-\eta \nabla^{2}\left(\nabla^{2}\left(u^{\prime}\right)\right)$

$\rho\left\{\frac{\partial w^{\prime}}{\partial t^{\prime}}+u^{\prime} \frac{\partial w^{\prime}}{\partial r^{\prime}}+w^{\prime} \frac{\partial w^{\prime}}{\partial z^{\prime}}\right\}=-\frac{\partial p^{\prime}}{\partial z^{\prime}}+\mu\left\{\frac{\partial}{\partial r^{\prime}}\left(\frac{1}{r} \frac{\partial\left(r^{\prime}, w^{\prime}\right)}{\partial r^{\prime}}\right)+\frac{\partial^{2} w^{\prime}}{\partial z^{\prime 2}}\right\}-\eta \nabla^{2}\left(\nabla^{2}\left(w^{\prime}\right)\right)$

Where $\nabla^{2}=\left\{\frac{\partial}{\partial r^{\prime}}\left[\frac{1}{r^{\prime}}\left(\frac{\partial\left(r^{\prime}\right)}{\partial r^{\prime}}\right)\right]\right\}$

Where $u^{\prime}$ and $w^{\prime}$ are the velocity components in the $r^{\prime}$ and $w^{\prime}$ direction respectively, $\rho$ is the density, $p^{\prime}$ is the pressure and $\mu$ is the viscosity, $\eta$ is the couple stress parameter.

The boundary conditions are

$u^{\prime}=0, \quad w^{\prime}=V_{0}^{\prime}, \quad \nabla^{2}\left(w^{\prime}\right)$ finite at $r^{\prime}=r_{1}^{\prime}$

$u^{\prime}=\frac{\partial r_{2}^{\prime}}{\partial t^{\prime}}, w^{\prime}=0 \quad \nabla^{2}\left(w^{\prime}\right)=0$ at $r^{\prime}=r_{2}^{\prime}$

It is convenient to non-dimensionalize the variable appearing in equation (2.1-2.6) sand introducing Reynolds number Re, wave number ratio $\delta$, and velocity parameter $V_{o}$ as follows:

$$
z=\frac{z^{\prime}}{\lambda^{\prime}}, \quad r=\frac{r^{\prime}}{c}, \quad u=\frac{\lambda u^{\prime}}{a_{20} c}, \quad p=\frac{a_{20}^{2}}{\lambda \mu c} p^{\prime}\left(z^{\prime}\right), \quad t=\frac{t^{\prime} c}{\lambda}, \quad \operatorname{Re}=\frac{\rho c a_{20}}{\mu},
$$

$\delta=\frac{a_{20}}{\lambda}, V_{0}=\frac{V_{o}^{\prime}}{c} \quad r_{1}=\frac{r_{1}^{\prime}}{a_{20}}=\varepsilon, \quad r_{2}=\frac{r_{2}^{\prime}}{a_{20}}=1+\frac{\lambda k z}{a_{20}}+\phi\left(\frac{2 \pi}{\lambda}(z-t)\right.$

where $\phi($ amplitude ratio $)=\frac{b}{a_{20}} \leq 1$

The equation of motion and boundary conditions in the dimensionless form becomes

$$
\begin{aligned}
& \frac{1}{r} \frac{\partial(r u)}{\partial r}+\frac{\partial w}{\partial z}=0 \\
& \operatorname{Re} \delta^{3}\left\{\frac{\partial u}{\partial t}+u \frac{\partial u}{\partial r}+w \frac{\partial u}{\partial z}\right\}=-\frac{\partial p}{\partial r}+\delta^{2} \frac{\partial}{\partial r}\left(\frac{1}{r} \frac{\partial(r u)}{\partial r}\right)+\delta^{4} \frac{\partial^{2} u}{\partial z^{2}}-\frac{\delta^{2}}{\gamma^{2}} \nabla^{2}\left(\nabla^{2}(u)\right)
\end{aligned}
$$




$$
\operatorname{Re} \delta\left\{\frac{\partial w}{\partial t}+u \frac{\partial w}{\partial r}+w \frac{\partial w}{\partial z}\right\}=-\frac{\partial p}{\partial z}+\frac{\partial}{\partial r}\left(\frac{1}{r} \frac{\partial(r w)}{\partial r}\right)+\delta^{2} \frac{\partial^{2} w}{\partial z^{2}}-\frac{1}{\gamma^{2}} \nabla^{2}\left(\nabla^{2}(w)\right)
$$

Where $\gamma=\sqrt{\frac{\eta}{\mu a_{20}^{2}}}$ is the couple-stress fluid parameter

The boundary conditions are:

$$
\begin{aligned}
& \mathrm{u}=0 \quad \mathrm{w}=\mathrm{V}_{0} \quad \nabla^{2}(u, w) \text { finite at } \quad \mathrm{r}=r_{1}=\mathcal{E}, \\
& \mathrm{u}=\frac{\partial r_{2}}{\partial y} \quad w=0 \quad \nabla^{2}(u, w)=0, \quad \text { at } r=r_{2}=1+\frac{\lambda k z}{a_{20}}+\phi \sin [2 \pi(z-t)]
\end{aligned}
$$

Using the long wavelength approximation and dropping terms of order $\delta$ it follows from equation (2.8-2.11) that the appropriate equation describing the flow in the laboratory frame of reference are

$$
\begin{aligned}
& \frac{\partial p}{\partial r}=\mathrm{O}, \\
& \frac{\partial p}{\partial z}=\frac{1}{r} \frac{\partial}{\partial r}\left(r \frac{\partial w}{\partial r}\right)-\frac{1}{\gamma^{2}} \nabla^{2}\left(\nabla^{2}(w)\right)
\end{aligned}
$$

with dimensionless boundary condition

$$
\begin{aligned}
& \mathrm{w}=\mathrm{V}_{0} \nabla^{2}(u, w) \quad \text { finite } \text { at } \mathrm{r}=r_{1}=\mathcal{E}, \\
& w=0 \quad \nabla^{2}(u, w)=0 \quad \text { at } r=r_{2}=1+\frac{\lambda k z}{a_{20}}+\phi \sin [2 \pi(z-t)]
\end{aligned}
$$

Integrating equation and using the boundary condition one finds the expression for the velocity profile as

$$
\begin{aligned}
w(z, t)=-\frac{1}{4}\left(\frac{\partial p}{\partial z}\right)\left[\left(r_{2}^{2}-r_{1}^{2}\right)\left(\frac{\operatorname{In}\left(r / r_{1}\right)}{\operatorname{In}\left(r_{2} / r_{1}\right)}\right)-r^{2}+r_{1}^{2}\right]+\frac{1}{16 \gamma^{2}}\left(\frac{\partial p}{\partial z}\right)\left\{\left(r_{2}^{2}-r_{1}^{2}\right)^{2}\left(\frac{\left(\operatorname{In}\left(r / r_{1}\right)\right)^{2}}{\left(\operatorname{In}\left(r_{2} / r\right)\right)^{2}}\right)\right. \\
\left.-\left(r^{2}-r_{1}^{2}\right)^{2}\right\}+\frac{V_{0}}{\operatorname{In}\left(r_{2} / r_{1}\right)} \operatorname{In}\left(r / r_{2}\right)\left\{\frac { 1 } { 4 \gamma ^ { 2 } } \left\{\left(r_{2}^{2}-r_{1}^{2}\right)\left(\frac{\operatorname{In}\left(r / r_{1}\right)}{\operatorname{In}\left(r_{2} / r_{1}\right)}\right)\right.\right. \\
\left.\left.-r^{2}+r_{1}^{2}\right\}\right\}-2 \frac{V_{0}}{\operatorname{In}\left(r_{2} / r_{1}\right)} \operatorname{In}\left(r / r_{2}\right)
\end{aligned}
$$

The instantaneous volume flow rate $Q(z, t)$ is given by

$$
\begin{gathered}
\mathrm{Q}(\mathrm{z}, \mathrm{t})=\int_{r_{1}}^{r_{2}} 2 \pi r w d r=-\frac{\pi}{8} \frac{\partial p}{\partial z}\left\{\left(r_{2}^{2}-r_{1}^{2}\right)\left[r_{2}^{2}+r_{1}^{2}-\left(\frac{r_{2}^{2}-r_{1}^{2}}{\operatorname{In}\left(r_{2} / r_{1}\right)}\right)\right]\right\}-\pi V_{o}\left\{\frac{r_{1}^{2}-r_{2}^{2}}{\operatorname{In}\left(r_{2} / r_{1}\right)}+r_{1}^{2}\right\}+ \\
\frac{\pi}{32 \gamma^{2}}\left[\left(r_{2}^{2}-r_{1}^{2}\right)^{2}\left[\left(r_{2}^{2}+r_{1}^{2}\right)^{2}-\frac{\left(r_{2}^{2}-r_{1}^{2}\right)^{2}}{\operatorname{In}\left(r_{2} / r_{1}\right)^{2}}\right]\right]+\frac{\pi V_{0}}{8 \gamma^{2}}\left\{\frac{r_{1}^{2}-r_{2}^{2}}{2 \operatorname{In}\left(r_{2} / r_{1}\right)}+r_{1}^{2}\right\} \\
\left\{\left(r_{2}^{2}-r_{1}^{2}\right)\left[\left(r_{2}^{2}+r_{1}^{2}\right)-\frac{\left(r_{2}^{2}-r_{1}^{2}\right)}{\operatorname{In}\left(r_{2} / r_{1}\right)}\right]\right\}
\end{gathered}
$$

Or

$$
\frac{\partial p}{\partial z}=-8\left(\frac{Q / \pi \quad \operatorname{In}\left(r_{2} / r_{1}\right)+\frac{V_{0}}{2}\left(r_{1}^{2}-r_{2}^{2}\right)+V_{0} r_{1}^{2} \operatorname{In}\left(r_{2} / r_{1}\right)\left\{1+\frac{1}{8 \gamma^{2}} D\right\}}{\left(r_{2}^{4}-r_{1}^{4}\right) \operatorname{In}\left(r_{2} / r_{1}\right)-\left(r_{2}^{2}-r_{1}^{2}\right)^{2}\left\{1+\frac{1}{4 \gamma^{2}} D\right\}}\right)
$$

Where 
$\mathrm{D}=\left(r_{2}^{4}-r_{1}^{4}\right)-\frac{\left(r_{2}^{2}-r_{1}^{2}\right)^{2}}{\operatorname{In}\left(r_{2} / r_{1}\right)}$

The pressure rise $\Delta p_{L}(t)$ and friction force (at the wall) on the outer and the inner tubes $F_{L}^{(o)}(t)$ and $F_{L}^{(i)}(t)$ respectively, in a tube of length $\mathrm{L}$, in their non-dimensional forms, are given by

$$
\begin{aligned}
& \Delta p_{L}(t)=\int_{0}^{A} \frac{\partial p}{\partial z} d z \\
& \Delta F_{L}^{(o)}(t)=\int_{0}^{A} r_{2}^{2}\left(-\frac{\partial p}{\partial z}\right) d z, \\
& \Delta F_{L}^{(i)}(t)=\int_{0}^{A} r_{1}^{2}\left(-\frac{\partial p}{\partial z}\right) d z,
\end{aligned}
$$

Where $\mathrm{A}=\mathrm{L} / \lambda$,

Substituting from equation (2.17) in equation (2.18-2.20) and with $r_{1}=\varepsilon$ and $r_{2}(z, t)=1+\frac{\lambda k z}{a_{20}}+\phi \sin [2 \pi(z-t)]$, we get

$$
\begin{aligned}
& \Delta p_{L}(t)=\int_{0}^{A}-8\left\{\frac{Q(z, t)}{\pi} \operatorname{In}\left[\frac{1+\frac{\lambda k z}{a_{20}}+\phi \sin 2 \pi(z-t)}{\varepsilon}\right]+\frac{V_{0}}{2}\left[\left(1+\frac{\lambda k z}{a_{20}}+\phi \sin 2 \pi(z-t)\right)^{2}-\varepsilon^{2}\right]\right. \\
& \left.+V_{0} \varepsilon^{2} \operatorname{In}\left[\frac{1+\frac{\lambda k z}{a_{20}}+\phi \sin 2 \pi(z-t)}{\varepsilon}\right]\right\}\left\{1+\frac{1}{8 \gamma^{2}} X\right\}\left\{1 /\left[\left(\left(\left[1+\frac{\lambda k z}{a_{20}}+\phi \sin 2 \pi(z-t]\right)^{4}-\varepsilon^{4}\right)\right.\right.\right. \\
& \left.\operatorname{In}\left[\frac{1+\frac{\lambda k z}{a_{20}}+\phi \sin 2 \pi(z-t)}{\varepsilon}\right]\left(1+\frac{1}{4 \gamma^{2}} X\right)\right\} d z \\
& \Delta F_{L}^{(o)}(t)=\int_{0}^{A} 8\left\{\left(1+\frac{\lambda k z}{a_{20}}+\phi \sin 2 \pi(z-t)\right)^{2}\right\}\left\{\frac{Q(z, t)}{\pi} \operatorname{In}\left[\frac{1+\frac{\lambda k z}{a_{20}}+\phi \sin 2 \pi(z-t)}{\varepsilon}\right]\right. \\
& \left.+\frac{V_{0}}{2}\left[\varepsilon^{2}-\left(1+\frac{\lambda k z}{a_{20}}+\phi \sin 2 \pi(z-t)\right)^{2}\right]+V_{0} \varepsilon^{2} \operatorname{In}\left[\frac{1+\frac{\lambda k z}{a_{20}}+\phi \sin 2 \pi(z-t)}{\varepsilon}\right]\right\} \\
& \left\{1+\frac{1}{8 \gamma^{2}} X\right\}\left\{1 /\left[\left(\left(\left[1+\frac{\lambda k z}{a_{20}}+\phi \sin 2 \pi(z-t]\right)^{4}-\varepsilon^{4}\right)\right.\right.\right. \\
& \left.\left.\left.\left(\left(1+\frac{\lambda k z}{a_{20}}+\phi \sin 2 \pi(z-t)^{2}-\varepsilon^{2}\right)^{2}\right)\left[1+\frac{1}{4 \gamma^{2}} X\right]\right\} d z\right\}\right\}
\end{aligned}
$$

$$
\begin{aligned}
& \Delta F_{L}^{(i)}(t)=\int_{0}^{A} 8 \varepsilon^{2}\left\{\frac{Q(z, t)}{\pi} \operatorname{In}\left[\frac{1+\frac{\lambda k z}{a_{20}}+\phi \sin 2 \pi(z-t)}{\varepsilon}\right]\right. \\
& +\frac{V_{0}}{2}\left[\varepsilon^{2}-\left(1+\frac{\lambda k z}{a_{20}}+\phi \sin 2 \pi(z-t)\right)^{2}\right]+V_{0} \varepsilon^{2} \operatorname{In}\left[\frac{1+\frac{\lambda k z}{a_{20}}+\phi \sin 2 \pi(z-t)}{\varepsilon}\right]
\end{aligned}
$$


$\left.\left\{1+\frac{1}{8 \gamma^{2}} X\right\}\right\}\left\{1 /\left[\left(\left(1+\frac{\lambda k z}{a_{20}}+\phi \sin 2 \pi(z-t)\right)^{4}-\varepsilon^{4}\right)\right.\right.$

$\left.-\left(\left(1+\frac{\lambda k z}{a_{20}}+\phi \sin 2 \pi(z-t)\right)^{2}-\varepsilon\right)\right]\left\{+\frac{1}{4 \gamma^{2}} X\right.$

Where

$$
\begin{gathered}
\mathrm{X}=\left\{( 1 + \frac { \lambda \mathrm { kz } } { \mathrm { a } _ { 2 0 } } + \phi \operatorname { s i n } 2 \pi ( \mathrm { z } - \mathrm { t } ) ^ { 2 } - \varepsilon ^ { 2 } ) \left[1+\frac{\lambda \mathrm{kz}}{\mathrm{a}_{20}}+\phi \sin 2 \pi(\mathrm{z}-\mathrm{t})^{2}+\varepsilon^{2}\right.\right. \\
\left.\left.-\left(\frac{1+\frac{\lambda \mathrm{kz}}{\mathrm{a}_{20}}+\phi \sin 2 \pi(\mathrm{z}-\mathrm{t})^{2}-\varepsilon^{2}}{1+\frac{\lambda \mathrm{kz}}{\mathrm{a}_{20}}+\phi \sin 2 \pi(\mathrm{z}-\mathrm{t})}\right)\right]\right\} \\
\operatorname{In}\left[\frac{1}{\varepsilon}\right]
\end{gathered}
$$

The limiting of equation (2.15-2.17) as $r_{1}$ tends to zero gives the forms of the axial velocity and the pressure gradient for peristaltic flow in non uniform tube(without endoscope, $\varepsilon=0$ ), these are

$$
\begin{aligned}
w(r, z, t) & =-\frac{1}{4}\left(\frac{\partial p}{\partial z}\right)\left(r_{2}^{2}-r^{2}\right)+\frac{1}{16}\left(\frac{\partial p}{\partial z}\right)\left(r_{2}^{4}-r^{4}\right), \\
\frac{\partial p}{\partial z} & =-\frac{8 Q}{\pi r_{2}^{4}}+\frac{16 Q}{\pi r_{2}^{16}},
\end{aligned}
$$

Hence the pressure rise and the outer friction force, in this case respectively, take the form

$$
\begin{aligned}
& \Delta p_{L}(t)=-8 \int_{0}^{A} \frac{[Q(z, t) / \pi] d z}{\left(1+\frac{\lambda k z}{a_{20}}+\phi \sin 2 \pi(z-t)\right)^{4}}+16 \int_{0}^{A} \frac{[Q(z, t) / \pi] d z}{\gamma^{2}\left(1+\frac{\lambda k z}{a_{20}}+\phi \sin 2 \pi(z-t)\right)^{16}} \\
& \Delta F_{L}^{(o)}(t)=8 \int_{0}^{A} \frac{[Q(z, t) / \pi] d z}{\left(1+\frac{\lambda k z}{a_{20}}+\phi \sin 2 \pi(z-t)\right)^{2}}+16 \int_{0}^{A} \frac{[Q(z, t) / \pi] d z}{\gamma^{2}\left(1+\frac{\lambda k z}{a_{20}}+\phi \sin 2 \pi(z-t)\right)^{4}}
\end{aligned}
$$

If $k=0$ in equations (2.26) and (2.27), we get expression for the pressure rise and friction force in a uniform tube. The analytical interpretation of our analysis with other theories are difficult to make at this stage, as the integrals in equation (2.21-2.23) and equation (2.26) and (2.27) are not integrable in closed form , neither for non-uniform nor uniform geometry $(\mathrm{k}=0)$. Thus further studies of our analysis are only possible after numerical evaluation of these integrals.

\section{RESULT, DISCUSSION AND CONCLUSION}

To discuss the results obtained above quantitatively assume the form of the instantaneous volume rate of the flow $Q$ ( $z, t)$, periodic in (z-t) as [2.14-2.16]

$$
\frac{Q(z, t)}{\pi}=\frac{\bar{Q}}{\pi}-\frac{\phi^{2}}{2}+2 \phi \sin (2 \pi(z-t))+\frac{2 \lambda k z}{a_{20}} \phi \sin (2 \pi(z-t))+\phi^{2} \sin ^{2}(2 \pi(z-t))
$$

where $\bar{Q}$ is the time average of the flow over one period of the wave. This form $\mathrm{Q}(\mathrm{z}, \mathrm{t})$ has been assumed in view of the fact that the constant value of $\mathrm{Q}(\mathrm{z}, \mathrm{t})$ gives $\Delta P_{L}(t)$ always negative, and hence will be no pumping action. Using this form of $\mathrm{Q}(\mathrm{z}, \mathrm{t})$, we shall now compute the dimensionless pressure rise $\Delta P_{L}(t)$, the inner friction force $F_{L}^{(i)}(t)$ (on the inner surface) and the outer friction force $F_{L}^{(o)}(t)$ (on the outer tube) over the tube length for various value of the dimensionless time t, dimensionless flow average $\bar{Q}$, amplitude ratio $\phi$, radius ratio $\mathcal{E}$, couple stress parameter $\gamma$ ,and the velocity of the inner tube $\mathrm{V}_{0}$. The average rise in pressure $\Delta \bar{P}_{L}$, outer friction force $F_{(L)}^{-(o)}$ and the inner friction force $F_{L}^{-(i)}(t)$ are then evaluated by averaging $\Delta P_{L}(t), F_{L}^{(o)}(t) \quad$,and $F_{L}^{(i)}(t)$ over one period of the wave. As integrals 
in equation (2.21-2.23) are not integrable in closed form, they are evaluated numerically using digital computer. Following Srivastava [15], we use the value of the various parameters in equation (2.21-2.23) as:

$$
\mathrm{a}_{20}=1.25 \mathrm{~cm}, \quad \mathrm{~L}=\lambda=8.01 \mathrm{~cm} \quad k=\frac{3 a_{20}}{\lambda} .
$$

Furthermore, since most routine upper gastrointestinal endoscopes are between 8-11 mm in diameter as reported Cotton and Williams [22] and the radius of the small intestine is $1.25 \mathrm{~cm}$ as reported in Srivastava [20] then the radius ratio $\mathcal{E}$, take the values $0.32,0.38$, and 0.44 .

Figure (1) and (4) represent the variation of the dimensionless pressure with dimensionless time $t$ for $\phi=0.4, V_{0}=0$, $\gamma=0.2$ and radius ratio $\varepsilon=0.32,0.38$, and 0.44 in the case of uniform and non uniform tube respectively. The difference of the pressure for different values of $\varepsilon$ becomes smaller as the radius ratio increases, i,e as the inner radius of the tube increases. It can also be seen that the effect of increasing the flow rate is to reduce the pressure rise for various values of $\mathcal{E}$

Fig (2) and (3) represent the variation of the dimensionless pressure rise with dimensionless time $t$ for $\phi=0.4, V_{0}=0$, $\gamma=0.2$ and velocity $\mathrm{V}_{0}=-1,0,1$ for non uniform and uniform tube respectively. The result shows that the pressure rise increases as the inner tube velocity increases, i.e. pressure rise for the endoscope increases as the inner tube moves in the direction of the peristaltic waves.

Fig (6)-(7) and (8) shows the inner friction force (on the inner surface) and outer friction forces (on the outer surface) are plotted versus dimensionless time $t$ for different values of $\varepsilon=0.32,0.38$, and 0.44 . It observed that as the radius ratio increases there is decrease in the inner friction force. It is noticed that the inner friction force behaves similar to the outer friction force for the same values of the parameter. Moreover, the outer friction force is greater than the inner friction force at the same values of the parameter.

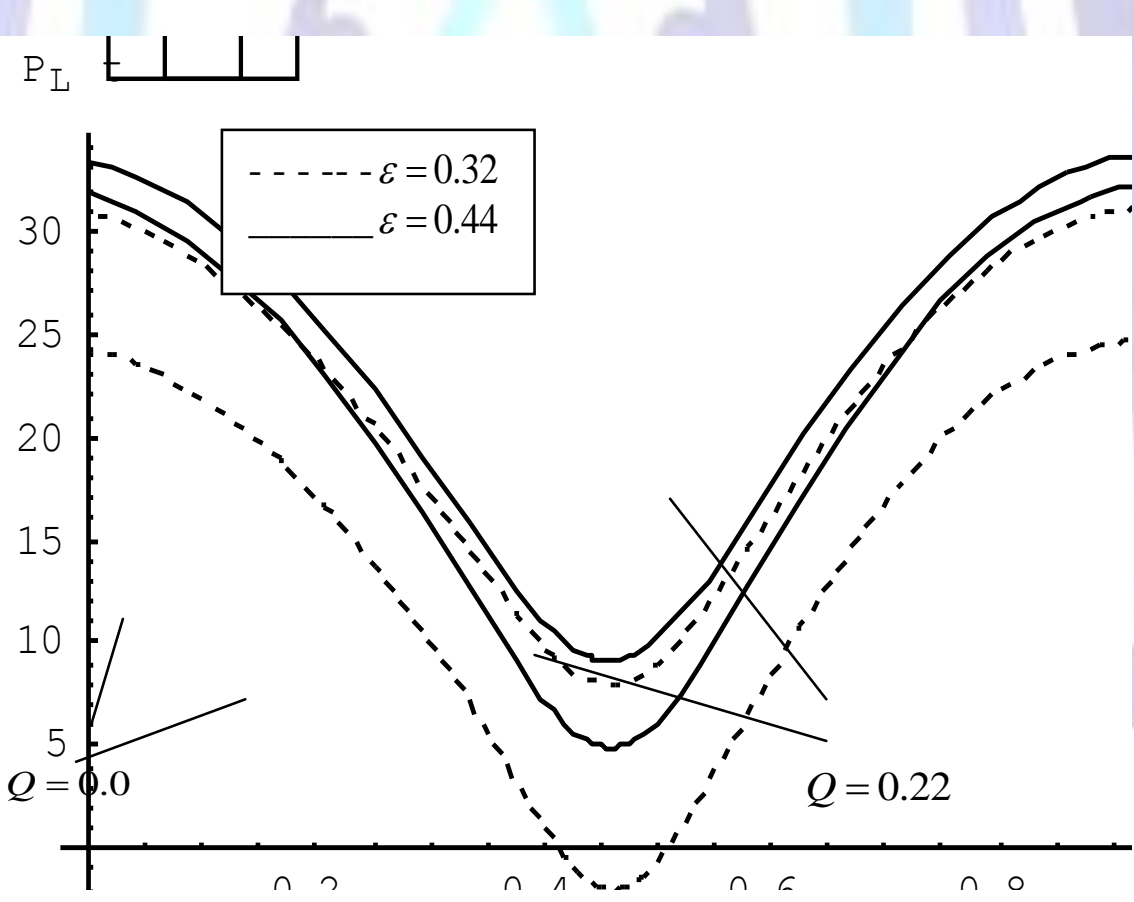

Fig (1) Variation of of pressure rise over the length of a uniform annulus at $\gamma=0.2 \phi=0.4, \quad \mathrm{~V}_{0}=0$ and different values of $\delta$ 


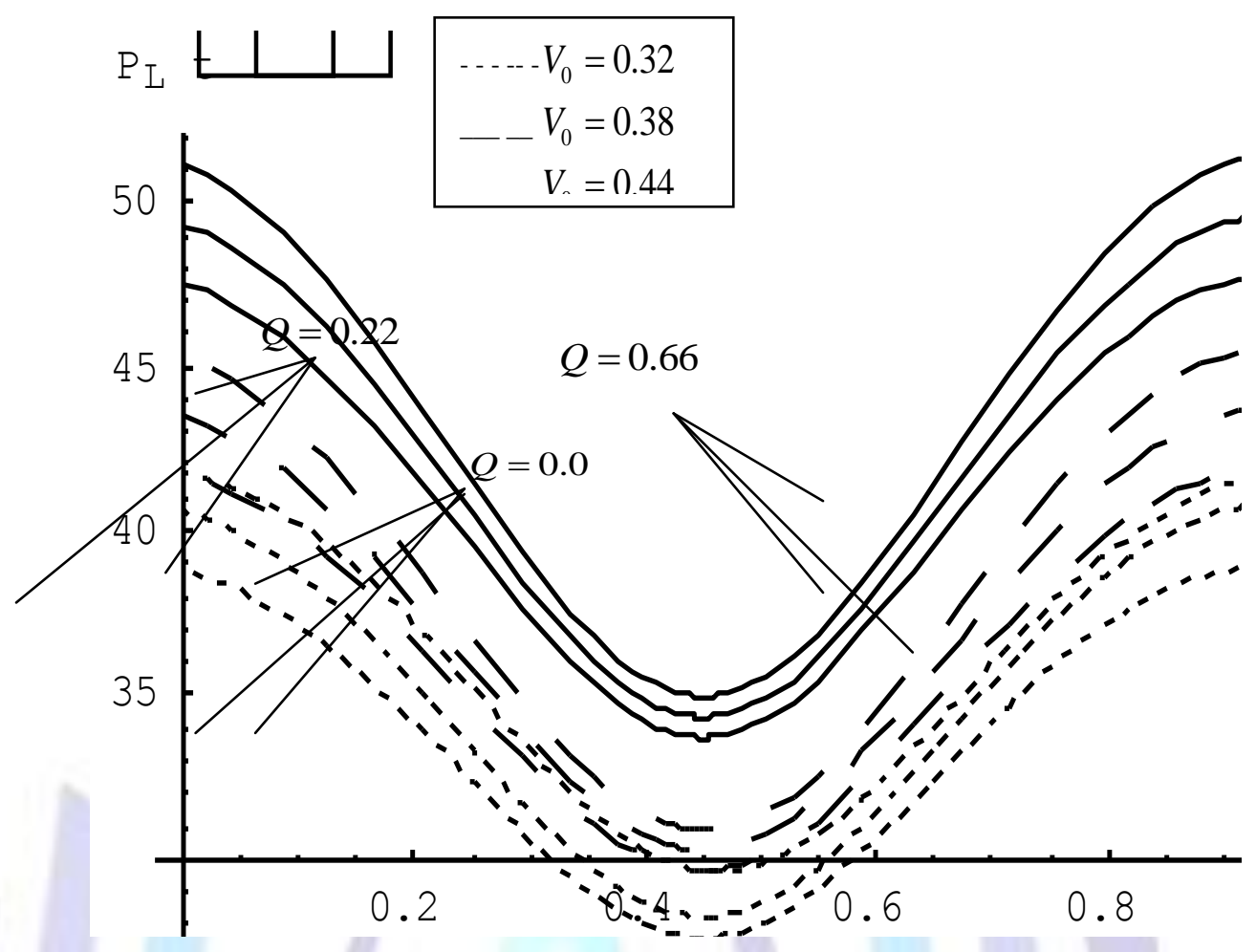

Fig (2) Variation of Pressure rise over the length of a non-uniform annulus at $\gamma=0.2$ for different values of $V_{0}$ at

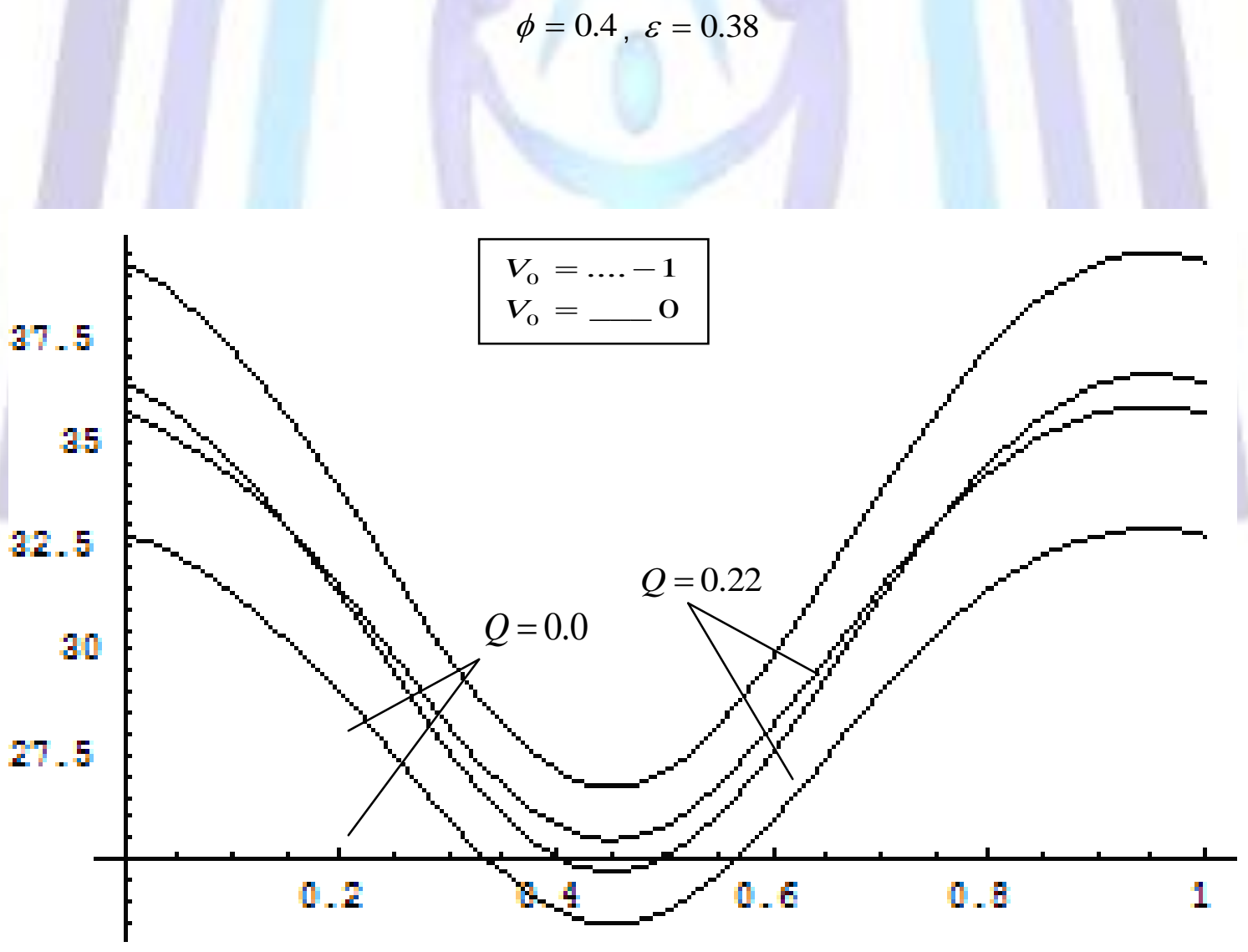

Fig.(3)Variation of pressure rise over the length of a uniform annulus

at $\gamma=0.2, \phi=0.4, \varepsilon=0.38$ for different values of $\mathrm{V}_{0}$ 


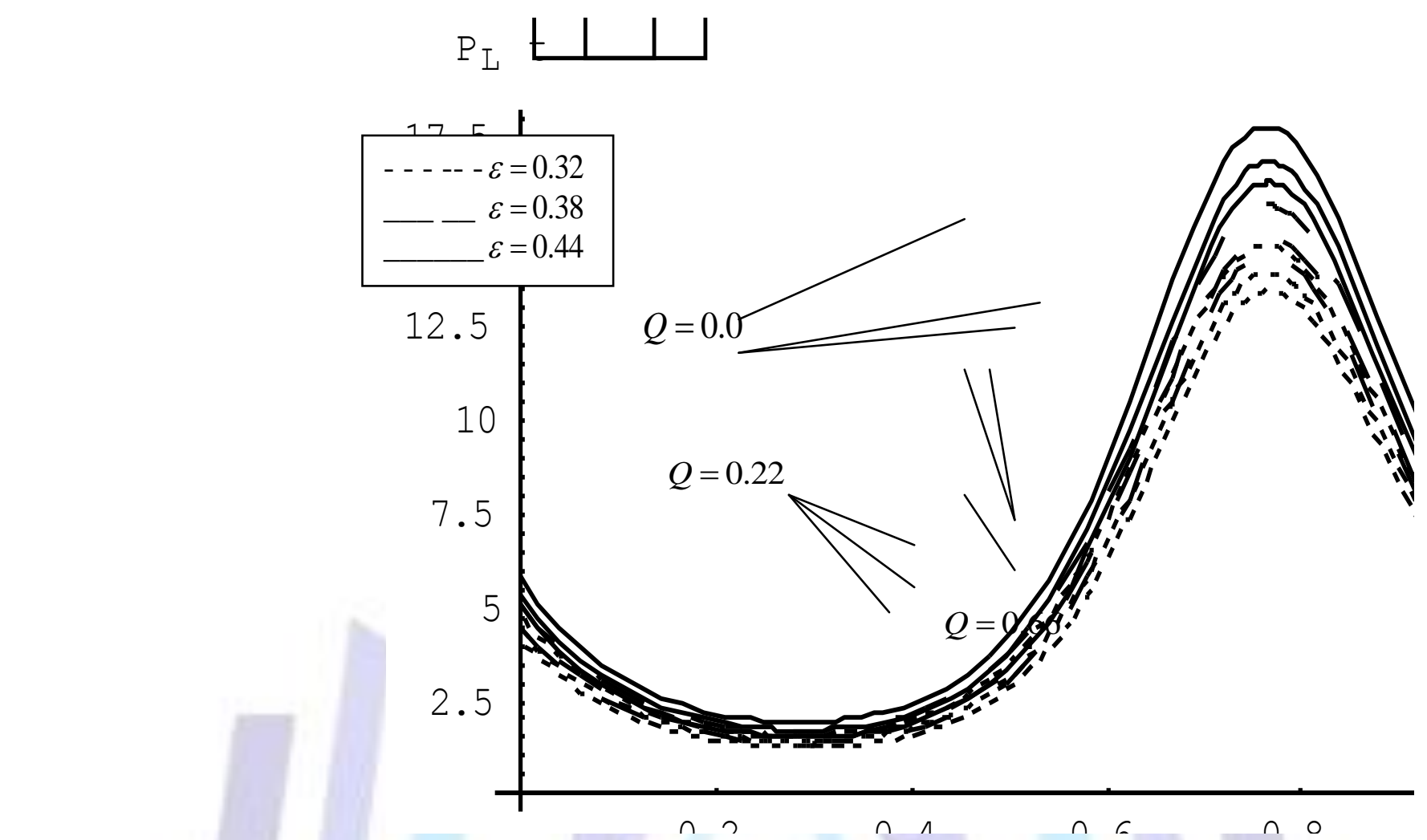

Fig (4) Variation of pressure rise over the length of non uniform at at $\gamma=0.2 \phi=0.4, \mathrm{~V}_{0}=0$ and different values of $\varepsilon$

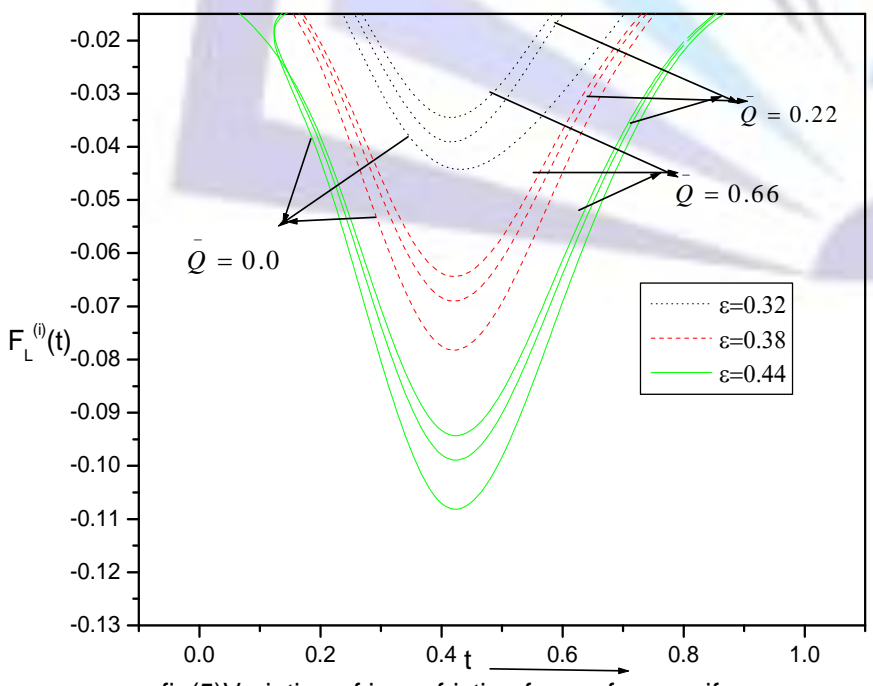

fig(5)Variation of inner friction force of non uniform annulus at $\gamma=0.2, \phi=0.4$,for different values of $V_{\circ}$ at $\varepsilon=0.38$

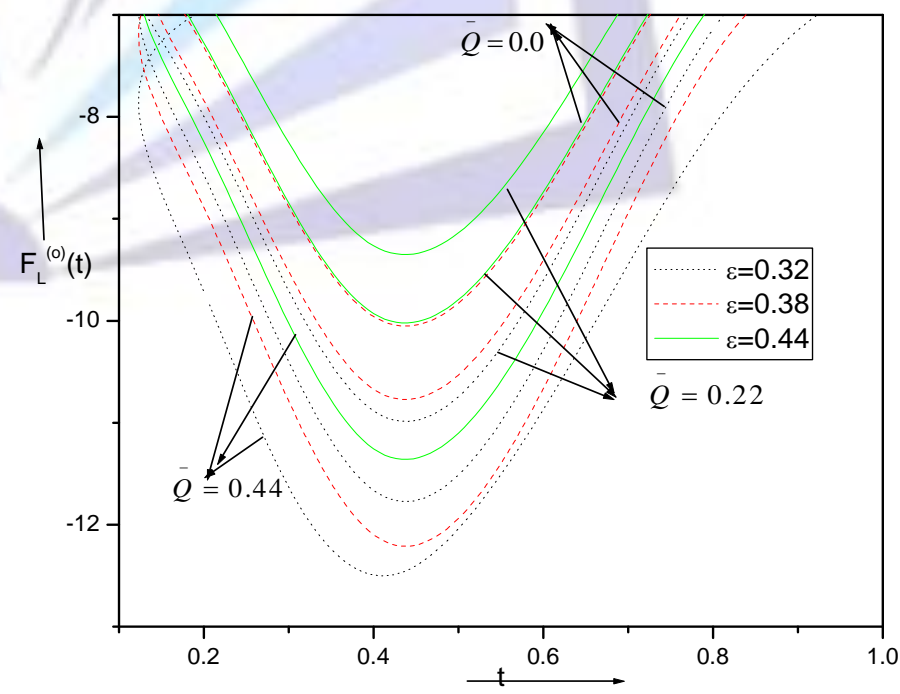

fig(6)Variation of the outer force over the length of a non-uniform at $\gamma=0.2, \phi=0.4$, and different values of $\varepsilon$ at $\mathrm{V}_{0}=0$ 


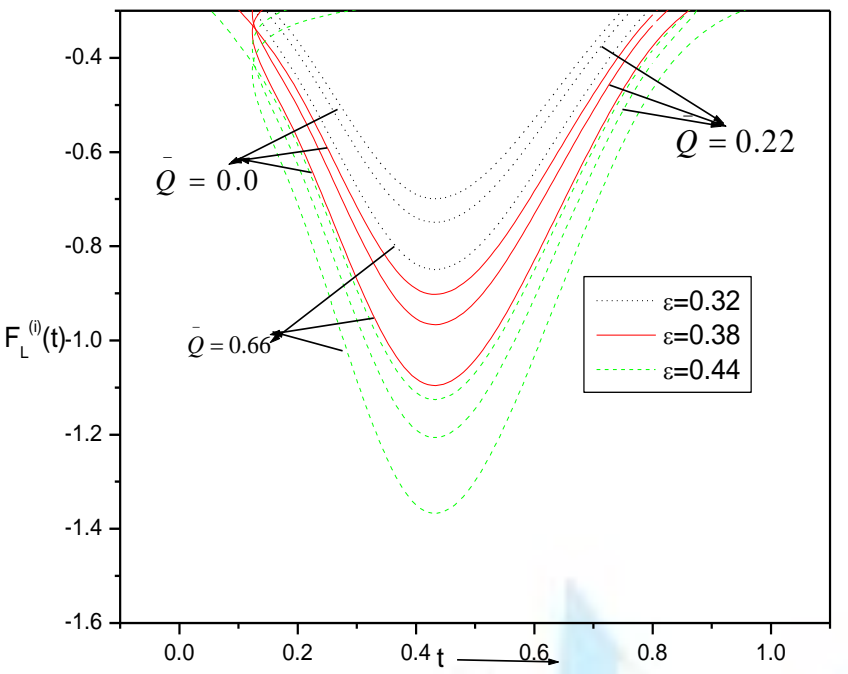

fig(7) Variation of inner friction force over the length of non uniform annulus at $\gamma=0.2, \phi=0.4$,for different values at $V_{0}=0$

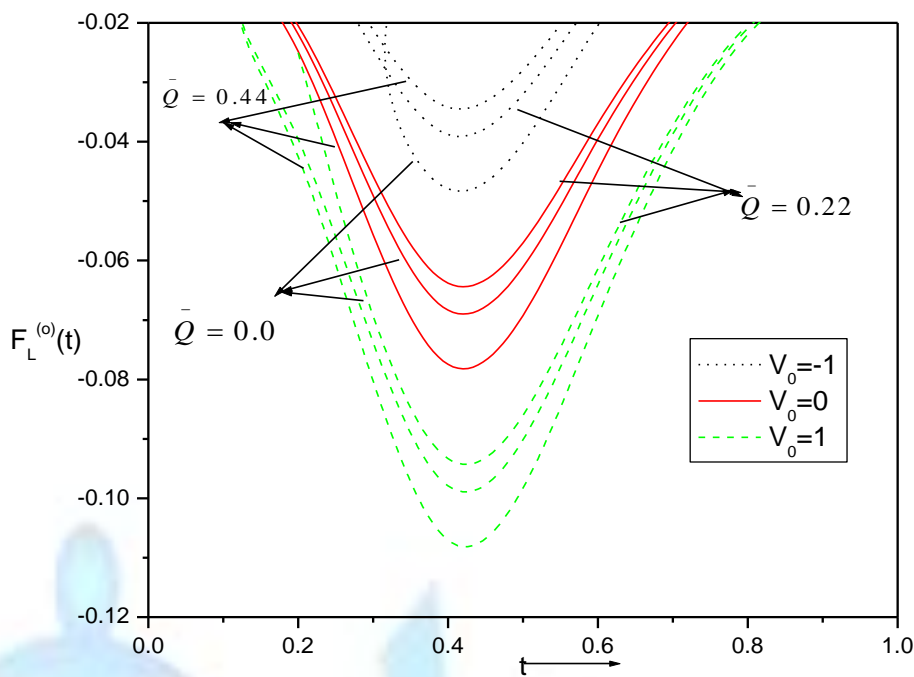

fig(8)Variation of the outer friction force over the length of non-uniform annulus at $\gamma=0.2, \phi=0.4$, and different values of $\mathrm{V}_{0}$ at $\varepsilon=0.38$

\section{Reference}

1. Shapiro A.H, Jaffrin M.Y. and.Weinberg, S.L "Peristaltic pumping Long Wave at Low Reynolds Number" J.Fluid Mech., 37(1969), pp. 799-825

2. Zien T.T. and Ostrach S.A “ A Long Wave Approximation to Peristaltic Motion”, J.Biomech,3 (1970), p.63

3. Elshehawey L.T. and Kh.S.Mekheimer, "Couple Stress in Peristaltic Transport of Fluids" J.Phys, D: Appl. Phys, 27 (1994), p.1163.

4. Ramachandra R.A and Usha S. "Peristaltic Transport of Two Immiscible Viscous Fluids in a Circular Tube", J.Fluid Mech., 298 (1995), p.271

5. Kh.S.Mekheimer Elsayed, L.El. Shehawey, and Elaw A.M. "Peristaltic Motion of a Particle fluid Suspension in a Planar Channel", Int.J. of Theor .Phys. (IJTP) , 37 (11)

(1998), p. 2895.

6. Kh.S.Mekhemier , "Non Linear Peristaltic Transport a Porous Medium in an Inclined Planar Channel”, J.Porous Media, 6(3), (2003), pp. 189-201.

7. Kh.S.Mekhemier, "Peristaltic Tranport of a Couple Stress fluid in a Uniform and Non-Uniform Channels", Biorheol., 39 (2002), pp 755-765.

8. Kh.S.Mekhemier, "Non-Linear Peristaltic Transport of Magneto-Hydrodynamic Flow in an Inclined Planar Channel" AISE , 28 (2A) (2003)pp 183-201.

9. Takabatake S. and. Ayukawa K, "Numerical Study of two Dimensional Peristaltic Flows" , J. Fluid Mech.,122 (1982), p 439.

10. Takabatake S. and. Ayukawa K,, "Peristaltic Pumping in Circular Cylindrical Tubes a Numerical Study of Fluid Transport and its Efficiency", J. FluidMech.,193 (1988).

11. Tang and Shen $M$ "Non Stationary peristaltic and transport of a heat conducting fluid, J.of Math. Anal. And Appl., 174 (1) (1993), p 265.

12. Brown T.D. and Hung T.K "Computational and Experimental Investigations of Two Dimensional Non-Linear Peristaltic Flows", J.Fluid Mech., 83 (1977), p. 249.

13. T.W.Latham, "Fluid Motion in a Peristaltic Pump”, M.Sc.Thesis ,MIT, Cambridge MA (1966).

14. Srivastava L.M. and Srivastava V.P. "Peristaltic Tranport of Blood Casson-II”, J. Biomech. 17(1984),p. 821-829.

15. Srivastava V.P and Saxena M. "A Two Fluid Model of Non-Newtonian Blood Flow Induced by Peristaltic Waves". Rheol.Acta, 33(1994), p.111.

16. Lee J.S. and Hung Y.C. "Flow in Non - Uniform Small Blood Vessel”,Microcir. Res.,3 (1971), pp. $272-279$.

17. Wiedeman M.P, "Dimension of Blood Vessel from Distributing Artery to Collecting Vein"Circ. Res., 12(1963), pp 375-381. 
18. Guha S.K. .Kaur and .Ahmed, Mechanics of Spermatic Fluid

19. Srivastava L.M. and Srivastava V.P. and.Sinha S.K, "Peristaltic Transport of a Physiological Fluid: Part I Flow in Non- Uniform Geometry” Biorheol., 20 (1983), pp. 428-433.

20. Srivastava L.M. and Srivastava V.P. "Peristaltic Transport of a Power-Law Fluid: Application to the Ductus Efferentes of the Reproducative Tract" Rheo.Acta, 27 (1988), pp 428-433.

21. Gupta B.B. and Sheshadri V, Peristaltic Pumping in Non-Uniform Tubes”, J.Biomech.9 (1976), pp. 105-109.

22. Cotton P.B. and Williams C.B., Practical Gastrointestinal Endoscopy, London:Oxford University Press Third Edition, (1990).Paper Received 18 March 2003,Revised 12 October 2003; Accepted 13 January 2004.

23. Asha S K and V.P.Rathod "Peristaltic Transport of magnetic fluid in Uniform and Non-Uniform Annulus" International journal of Mathematical Archive , 2(12) 2011, pp 2802-2012.

24. Asha S K and V.P.Rathod "Effect of magnetic field and an endoscope on peristaltic motion" Advance in applied Science Research, 2(4), 2012, pp 102-109

25. Rathod and Shridhar "Peristaltic Transport of a couple stress fluid in uniform and non- uniform annulus through porous medium" International journal of Mathematical Archive

3(4) 2012, pp 1561-1574

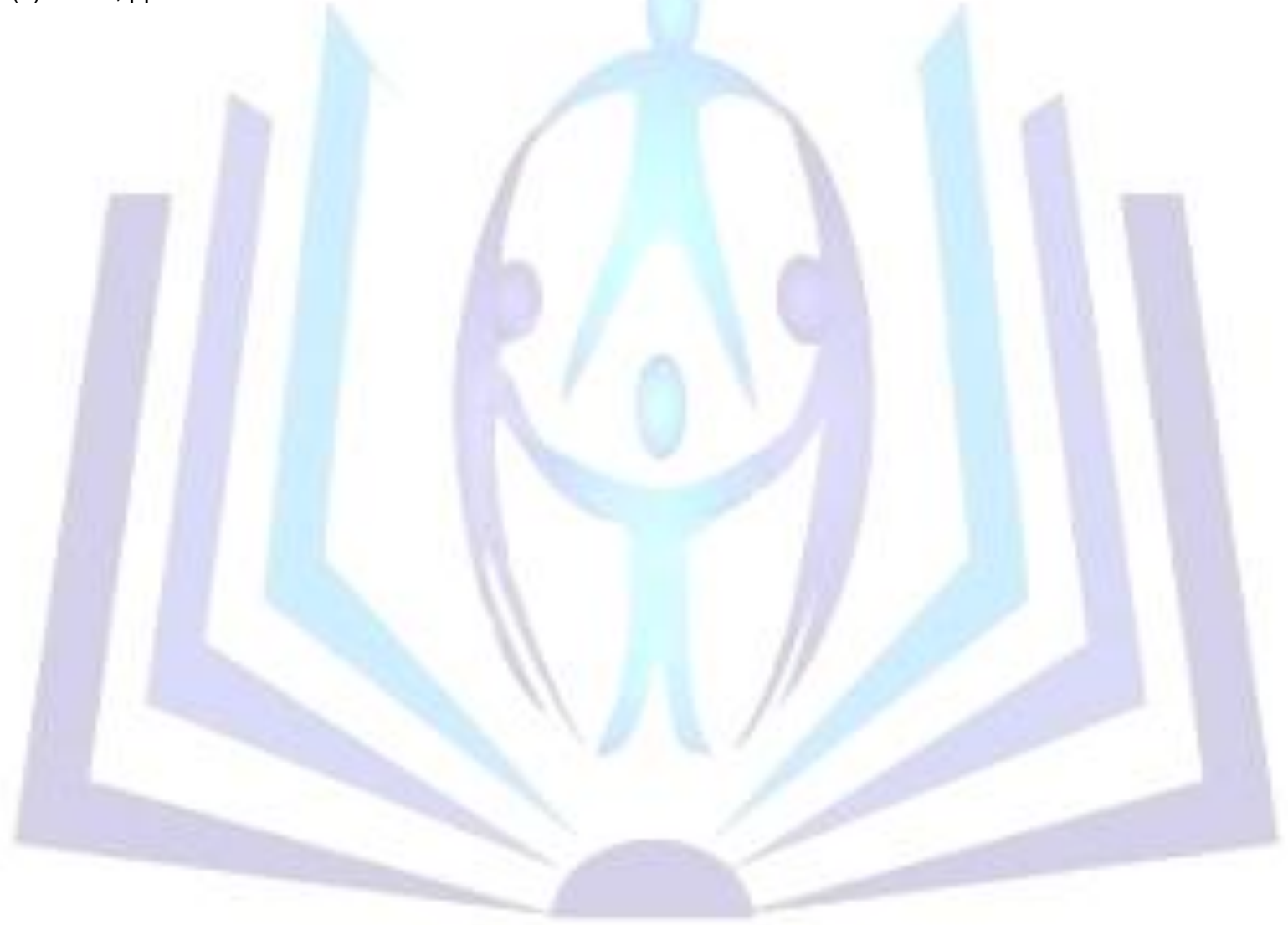

